\title{
FPGA TABANLI 5 EKSENLİ MOBİL ROBOT KOLU TASARIMI VE PROTOTİP GERÇEKLENMESİ
}

\author{
${ }^{1}$ Hasan KARCI, Ali TANGEL ${ }^{2}$ \\ ${ }^{1}$ Kocaeli Üniversitesi, Fen Bilimleri Enstitüsü, Umuttepe Yerleşkesi, 41380, İzmit, Kocaeli \\ ${ }^{2}$ Kocaeli Üniversitesi, Mühendislik Fakültesi, Elektronik-Haberleşme Mühendisliği Bölümü, Umuttepe \\ Yerleşkesi, 41380, İzmit, Kocaeli \\ hsnkarci06@hotmail.com, atangel@kocaeli.edu.tr
}

(Geliş/Received: 18.04.2013; Kabul/Accepted: 29.12.2015)

ÖZET

$\mathrm{Bu}$ çalışmada, mobil bir aracın üzerine monte edilmiş 5 eksenli bir robot kolu ile cisimleri bir ultrasonik sensör aracılığı ile tanıyıp boyutlarına göre ayırt edebilen, tümüyle otonom olarak çalışabilen FPGA tabanlı bir robotik sistem gerçeklenmiştir. Ultrasonik sensörden alınan veriye göre mobil aracın hız ve konum kontrolü ile robot kolunun konum kontrolüne ait sayısal tasarım tek bir FPGA yongası üzerinde gerçeklenmiş̧ir. Mobil robot kolu üzerindeki DC motor ve DC-servo motorların sürücü devreleri ayrıca tasarlanarak, motorların hız ve konum kontrolü yine VHDL kodu ile oluşturulan PWM kontrol sinyalleri aracılığıyla sağlanmıştır. Bu çalışmada PWM sinyallerini üretmede frekans bölme tekniği kullanılmıştır. FPGA tabanlı tasarımların tasarımcıya sunduğu paralel işlem yapabilme yeteneği sayesinde, mobil robot kolu üzerindeki ünitelerin durumları aynı anda kontrol edilebilmiştir. VHDL ile oluşturulan tasarım kodu Xilinx ISE paket programı aracılığ 1 ile sentezlenerek, donanımın çalışması Modelsim benzetim programı aracılığıyla doğrulanmıştır. Daha sonra, yapılan tasarım Spartan-3 FPGA geliştirme kiti üzerinde gerçeklenmiştir. FPGA geliştirme kiti, gerçeklenen mobil robot donanımının bir parçası olarak mobil platform üzerine monte edilmiştir. Mobil robot kolunun beklenen tüm işlevlerini sorunsuz bir şekilde yerine getirdiği deneysel olarak da gözlenmiştir. Ayrıca, tasarımın literatürdeki bazı robot kolu tasarımları ile karşılaştırması, tasarım teknolojisi, robot türü ve serbestlik dereceleri bakımından farklılık içermesi sebebiyle ancak kategorik olarak yapılabilmiştir.

Anahtar Kelimeler: Mobil robot, FPGA, hız kontrolü, ultrasonik konum kontrolü

\section{DESIGN AND PROTOTYPE IMPLEMENTATION OF A 5-DOF MOBILE ROBOT ARM BASED ON FPGA}

\begin{abstract}
In this study, a FPGA based, mobile, fully autonomous, 5-DOF robot arm, which can distinguish objects according to their dimensions using an ultrasonic sensor module is designed and implemented. Digital hardware design of speed and position control of the vehicle carrying the robot arm and the position control of the robot arm are implemented on a single FPGA chip. The driver circuits of the DC motors and the RC motors mounted on the mobile robot arm system are also realized, and the motor speed and position controls are handled through the PWM signals obtained by a specific VHDL module. Frequency division technique is used to produce the PWM signals. The concurrent controls of the units mounted on the arm are possible due to parallel execution ability offered by FPGA based designs. The Modelsim program is used for VHDL code simulations. The real FPGA implementations are done on a Spartan-3 FPGA evaluation board using Xilinx ISE tools. This evaluation board is also mounted on the vehicle platform as a part of the mobile robot arm system. The test results show that the robot arm is able to accomplish all expected functions successfully. Finally, the designed robot arm is only categorically compared to some robot arm designs exist in the literature due to mismatch with design technology, robot type and DOF in all aspects.
\end{abstract}

Keywords: Mobile robot, FPGA, speed control, ultrasonic position control 


\section{GIIRIŞ (INTRODUCTION)}

Günümüz teknolojisinde robotların önemi giderek artmakta ve birçok endüstriyel, askeri ve diğer uygulamalarda insanın yerini almaktadır. Robotlar, özellikle robot kolları endüstride yaygın olarak kullanılmaktadır. Robotların çalışabilmesi için elektronik bir sisteme ihtiyaç vardır. Bu elektronik sistem içerisinde genelde işlemci, algılayıcılar ve sürücü devreleri yer alır. Donanımın genel hatlarını değiştirmeden sistemin güncellenmesi, maliyeti oldukça düşürür. Maliyetin yanında zaman tasarrufu için hızlı yazılım ve donanım adaptasyonu gereklidir. Geleneksel devre tasarımlarında, herhangi bir uygulamada kullanılacak devreler üretim esnasında yapılandırılır iken, alan programlanabilir teknolojisinde ise üretimden sonra kapı seviyesinde ara bağlantılar son kullanıcı tarafindan donanımsal olarak yeniden yapılandırılabilirler. Alan programlama teknolojisinin tasarımciya sunduğu bu esneklik sayesinde, tekrar programlanabilen, yani uygulama geliştirmeye açık tasarımlar mümkün olabilmektedir. FPGA lerin uygulama alanlarından biri de robot teknolojileridir. Robot teknolojisinde ise robotun yapacağı işler esneklik kazandıkça robotun kullanılabilirliği artmaktadır. FPGA'nın yeniden yapılandırılması ile robotik sistemlerdeki esneklik ihtiyacı giderilebilmektedir. Yakın geçmişe kadar robotik sistemlerin mikro denetleyici veya DSP çipleri kullanılarak gerçeklendiği bilinmektedir [1]. Mikrodenetleyici ve DSP ile oluşturulan robot kontrol sistemleri büyük kapasite ve hızlı yapılandırılabilme olanağını yeterince sağlayamamaktadır [1]. Çok eksenli bir robot kolu ile birlikte, kolu taşıyan mobil aracın ve bu aracın üzerindeki bir takım algılayıcıların bilgilerinin okunmasını, bunun yanında karar algoritmalarının gerçeklenmesini aynı anda düşündüğümüzde, önümüze hem karmaşık hem de esneklik isteyen bir tasarım problemi çıkmaktadır. Bu da tasarımın çok sayıda bileşen içermesini gerektirmektedir. Birçok modülün eşzamanlı olarak kullanılmasıyla, modüler robotlar kontrol edilebilirlik açısından daha karmaşı hale gelebilmektedir. $\mathrm{Bu}$ nedenle tekdüze çalışan mimariler, birçok bileşen içeren robot tasarımında, robotların çeşitli fonksiyonları gerçekleştirmesinde yeterli olamamaktadır [2]. Çok eksenli robot manipülatöründe oluşturulan hareket kontrol algoritmasının bileşenlerinin FPGA ile kontrolü günümüzde mümkün olmaktadır [3]. Literatürdeki FPGA tabanlı robot uygulamalarına örnek olarak bazı çalışmalar özetlenecek olursa, [2] nolu çalışmada, dinamik olarak yeniden konfigüre edilebilen FPGA ve ARM tabanlı mobil bir robot kolu tasarımı karşımıza çıkmaktadır. Robotun hareket kontrolü uzaktan ZigBee modülü yardımıyla sağlanmaktadır, dolayısı ile tümüyle otonom bir sistem değildir. Sistem çok eksenli bir yapıya sahiptir ve FPGA modülünün dinamik olarak yeniden yapılandırılması FPGA ile aynı veri yoluna bağlı bir ARM işlemci tarafindan gerçekleştirilmektedir. Sistem üzerinde algılayıcı modüller veya kamera bulunmamaktadır. Sistemde kontrol edilen 8 servo motor ile mobil platformun hareketini kontrol eden 4 adet DC motor mevcuttur. [3] nolu çalışmada ise karmaşık olan ters kinematik hesaplamaların ve servo motor kontrollerinin tek bir FPGA yongası üzerinde yapıldığı çok eksenli bir robot uygulaması gerçeklenmiştir. Tasarım Xilinx XC2V6000-FF1152 platformu üzerinde gerçeklenmiştir. FPGA kaynak kullanımı doğal olarak oldukça fazladır. Sistem aynı anda en fazla 4 ekseni kontrol edebilmektedir. Motorlar bir PID kontrolör modülü tarafindan, tanımlanan bir hız profiline göre hareket etmektedir. Komutlar sisteme bağlı bir PC tarafindan iletilmektedir. [4] nolu çalışmada ise eğitim amaçlı, FPGA ve ARM tabanlı mobil bir robot araba sistemi gerçeklenmiş̧ir. Sistem üzerinde 5 farklı sensör kullanılmıştır. ARM işlemci üzerinde koşan yüksek düzeyli bir programlama dili (Java) ile yeniden yapılandırılabilir bir platform özelliğindedir. Öğrenciler üzerinde çeşitli geliştirmeler yapabilir. [5] nolu çalışma FPGA lerin robotik sistemlerde kullanımına yönelik bir başka örnek çalışmadır. Burada harici bir işlemci kullanımı yerine bir Altera FPGA içerisinde gömülü Nios işlemci kullanımına gidilmiştir. Buradaki Nios işlemci, komutların üretilmesi, ters kinematik hesaplamalar ve noktadan noktaya hareket kontrolü için kullanılmıştır. Bu kısım FPGA tasarımının içindeki iki iyelik çekirdeği (IP) den biridir. Diğer IP ise uygulama amacına yönelik olup 5 eksenli robot kolunun hareketini kontrol içindir. Bu çalışmada ise FPGA tabanlı esnek tasarım örneği olarak 5 eksenli mobil bir robot kolu tasarımı ve prototip üretimi gerçeklenmiştir. Belirli bir amaca yönelik olarak sistem tümüyle otonom olarak çalışmaktadır. Karmaşık ters kinematik hesaplamalara girilmeden, ultrasonik sensör yardımıyla düşük maliyetli bir FPGA platformu üzerinde tüm sayısal tasarım gerçeklenebilmiştir. Makalenin geri kalan bölümlerinde tasarım adımları detaylı olarak anlatılmış, benzetim ve test sonuçları verilmiştir. $\mathrm{Bu}$ makale çalışması ilgili yazarların ELECO'2012 isimli konferansta sunmuş oldukları [6] nolu bildirideki çalışmanın genişletilmiş ve revize edilmiş versiyonudur.

\section{MOBILL ROBOT KOLU (THE MOBILE ROBOT ARM)}

Mobil robot kolu, 5 serbestlik derecesine sahip bir robot kolu ve üzerine bir adet ultrasonik sensör modülü monte edilmiş dört tekerlekli bir mobil araçtan oluşmaktadır. Robot kolu mekanik aksamı hazır olarak satın alınmıştır ve tarafimızca gerçeklenen, birbirinden bağımsız sürücü devreleri ile kontrol edilen dört tekerlekli bir mobil platform üzerine monte edilmiştir. Şekil 1'de görüldüğü gibi, mobil araç platformu üzerine ayrıca bir adet Spartan-3 FPGA geliştirme kiti, motor sürücü devreleri ve bir adet akü yerleştirilmiştir. FPGA yongası 
yapılandırılarak, yapılandırma kablosu bağlantısı FPGA kitinden çıkartılır ve böylece serbest bir şekilde hareket sağlanmış olur. Motorların, sürücü devrelerin, ultrasonik sensör modülünün ve FPGA kitinin güç gereksinimi ise araç platformuna yerleştirilen aküden sağlanmıştır.

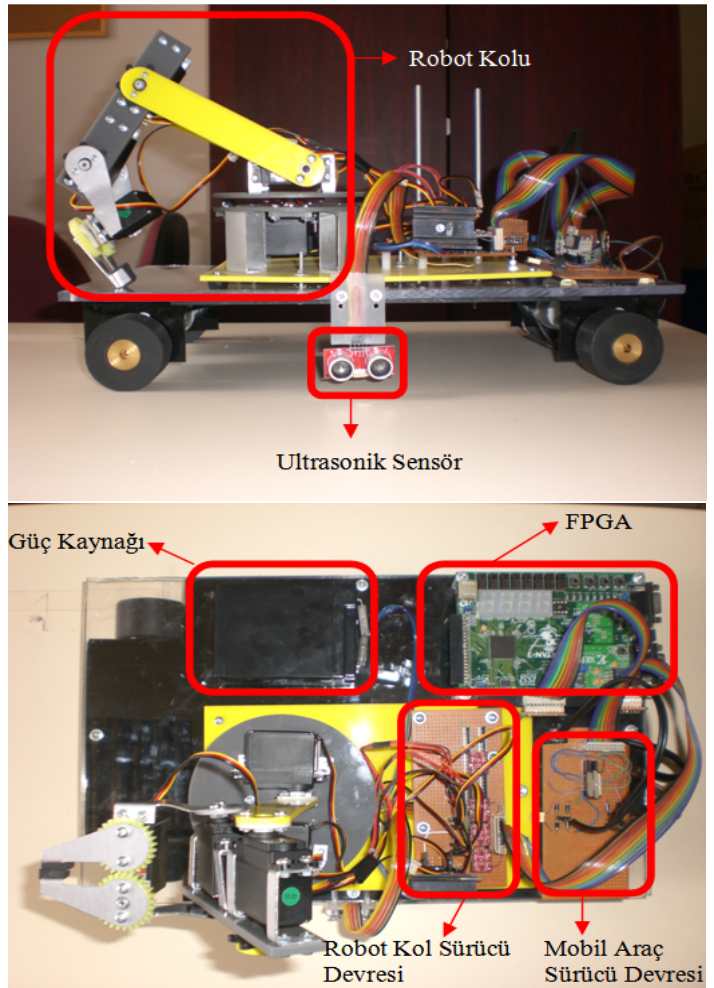

Şekil 1. Mobil robot kolunun yandan ve üstten görünümü (Side and top view of the robot arm)

Her bir modülün ihtiyaç duyduğu farklı gerilim seviyelerini üreten bir güç devresi de tasarlanmıştır. Robot kolu RC servo motora bağl1, 180 derece dönebilen bir taban üzerine yerleştirilmiştir. İnsan koluna benzetilirse, robot kolu omuz, dirsek, bilek ve tutucudan oluşmaktadır (Bknz. Şekil 2). Kolu oluşturan bileşenlerin geniş açı ile hareket etmeleri sayesinde robot kolu esneklik kazanmıştır. Robot kolu, ucundaki tutucusu yardımıla cisimleri tutup kaldırabilmektedir. Şekil 3'te verilen mobil robot kolunun genel blok diyagramından da anlaşılacağ 1 üzere, tasarlanan robot kolu, mobil araçla birlikte hareket edebilecek, ultrasonik sensör yardımıyla yanından geçtiği cisimleri boyutlarına göre ayırt edebilecek, cisimleri üzerine alma veya yerlerini değiştirme gibi işlevleri gerçekleştirebilecek donanımlara sahiptir. Mobil aracın hareketi, birbirinden bağımsız olarak sürülen 4 adet $\mathrm{DC}$ motorlara bağlı tekerleklerle yapılmıştır. Aracın hızı ve yönünün kontrolü PWM (Pulse Width Modulation) sinyali ile yapılmıştır. Mobil aracın yan tarafına yerleştirilen bir tane ultrasonik sensör modülü aracılığıyla hem aracın konumunun kontrolü hem de cismin boyutu tespit edilebilmiştir. Cismin konumuna ve boyuna göre, robot kolu cismi tutup kaldırmak amaciyla hareket edebilmektedir.

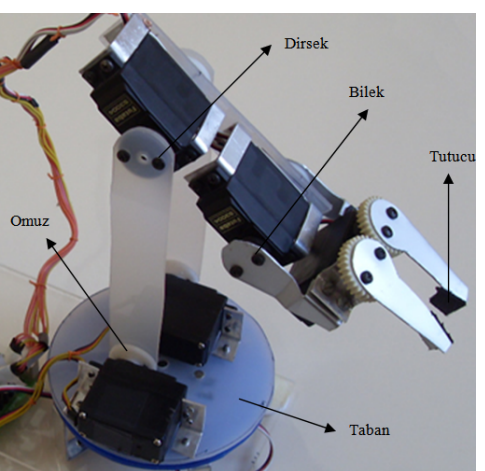

Şekil 2. Robot Kolu Eksen Yapısı (DOF structure of the robot arm)

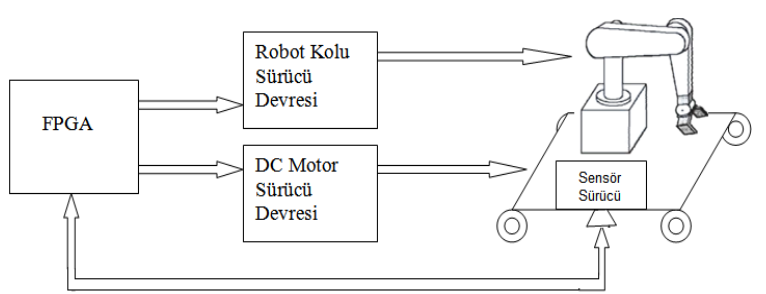

Şekil 3. Mobil Robot Kolu Blok Diyagramı (Block diagram of the mobile robot arm)

\section{FPGA KONTROL BLOKLARI (FPGA CONTROL BLOCKS)}

Mobil robotun kolunun kontrolü için FPGA üzerinde gerçeklenen donanım tasarımı kullanılmıștır. FPGA'nın yüksek kaynak kapasitesi, hızı ve esnekliği uygulama geliştirme için oldukça elverişlidir. Bu mobil robot kolu da FPGA kullanılarak tasarlanan robotik uygulamalara güzel bir örnek olușturmuștur. Mikro denetleyiciler ve DSP'ler yillarca motor kontrolünde kullanılmıştır. $\mathrm{Bu}$ aygıtlar tasarımla tümleşik oluyordu ve sadece yazılımsal bazı güncellemelere olanak sağliyordu. Fakat özel uygulamalar için sınırlı olanakları vardı [7]. FPGA' ların sağladığı esneklik ile motor çeşitlerine göre kontrol stratejileri kolaylıkla tekrar ayarlanabildi [8]. Motor kontrolleri için ardışıl olarak işleyen bir yazılım kodu oluşturulabilir, ama FPGA'nın paralel işlem yapma özelliğinden dolayı aynı anda çok sayıda prosesi paralel olarak çalıştırabilme üstünlüğü vardır.

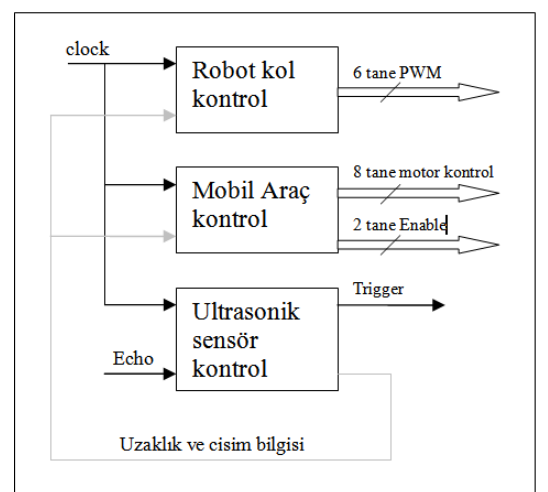

Şekil 4. Kontrol kodu blok diyagramı (Block diagram of the control code) 
Şekil 4’te verilen blok diyagramdan anlaşılacağı üzere toplam 17 adet sinyal aynı anda kontrol edilmiştir. Bu sinyallerden 6 tanesi robot kolunu oluşturan RC servo motorlar için PWM, 8 tanesi mobil araçtaki 4 adet DC motor için kontrol ve enable sinyali ile birlikte ultrasonik sensörün çalışması için trigger tetikleme sinyali olarak belirlenmiştir.

Şekil 5'de mobil robot kolunun çalışmasını gösteren akış diyagramı verilmiştir. Hareket halinde olan mobil araç, konumunu ultrasonik sensörden gelen bilgiye göre ayarlamaktadır. Tasarım mimarisi içinde yer alan mesafe sayacı sayesinde, gelen mesafe bilgisi sürekli olarak ilgili set değeriyle karşılaştırılır ve tekerleklerin dönüş hızı buna göre belirlenir. Tekerlek dönüş hızları ise üretilen PWM kontrol sinyaline göre ayarlanır.

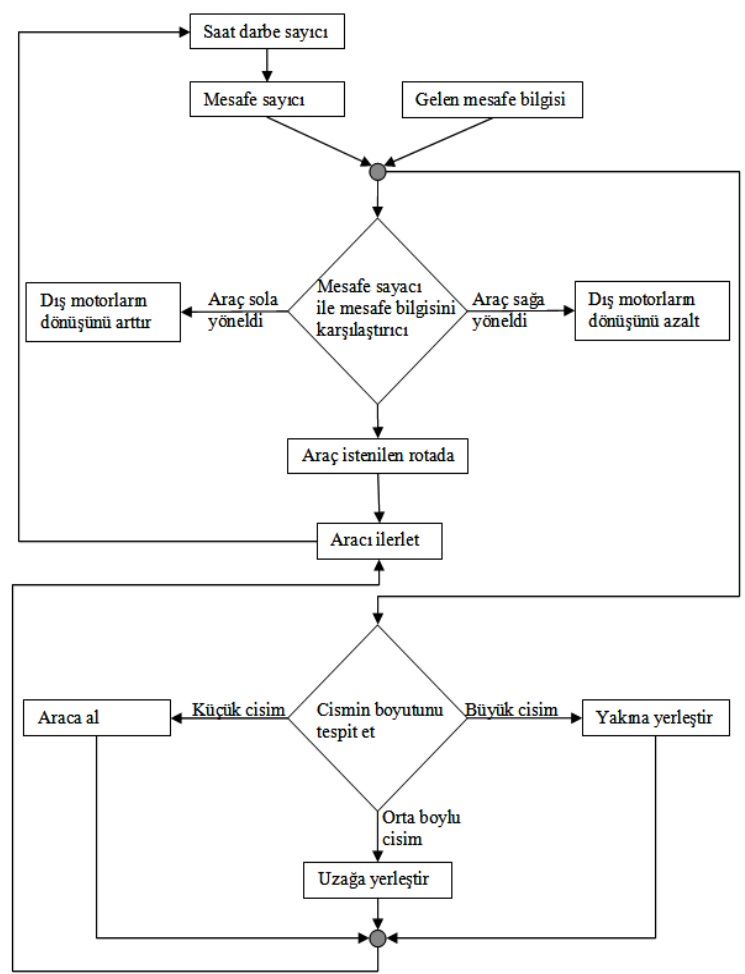

Şekil 5. Mobil robot kolu kontrol akış şeması (Flow chart of the mobile robot arm control)

Mobil robot, hareket esnasında cismi algılarsa cismin boyunu tespit eder ve robot kolu pozisyon komutları bu bilgiye göre şekillenir. Aynı zamanda cismin arabaya olan uzaklığına göre de robot kolu cisme uzanır. Mesafe bilgisi, tasarım algoritmasında çeşitli matematiksel işlemler yardımıyla robot kolunun konumunu belirlemede kullanılır. Mobil robot; robot kolu, mobil araç ve ultrasonik sensörden oluşmaktadır. $\mathrm{Bu}$ çalışmada tasarımın genel bileşenleri de üç ana kısımda incelenmiştir:

- Robot kolu kontrol bloğu

- Mobil araç üzerindeki DC motor kontrol bloğu

- Ultrasonik sensör kontrol bloğu
Ultrasonik sensör kontrol bloğundan gelen veriye göre diğer blokların akış algoritması şekillenir. Mobil araç hareket halinde iken ultrasonik sensörden gelen verilere göre mesafe ölçümleri değerlendirilir ve cisim algılandığında üzerinde işlem yapılır. Cisim mobil araca alınır veya cismin yeri değiştirir. Mobil araç, hareket güzergâhındaki cisimler bitene kadar bu işlemleri yapmaya devam eder.

\subsection{Robot Kolu Kontrol Bloğu (Control block of the robot arm)}

RC servo motor kontrolü için saniyede 50 defa tekrar eden ve 1 ile $2 \mathrm{~ms}$ arasında doluluk boşluk oranına sahip olan PWM sinyali kullanılmıştır (Bknz. Şekil 6). 5 eksenli robot kolu için 5 farklı PWM, FPGA üzerinde üretilmiştir. Servo motorlar için gerekli olan sinyalin periyod çerçevesi $20 \mathrm{~ms}$ olmalıdır. FPGA'nın çalışma frekansı $50 \mathrm{MHz}$ olduğu için kontrol bloğu içinde sayıcı yardımıyla $20 \mathrm{~ms}$ 'lik yerel saat darbesi oluşturulmuş̧tur.

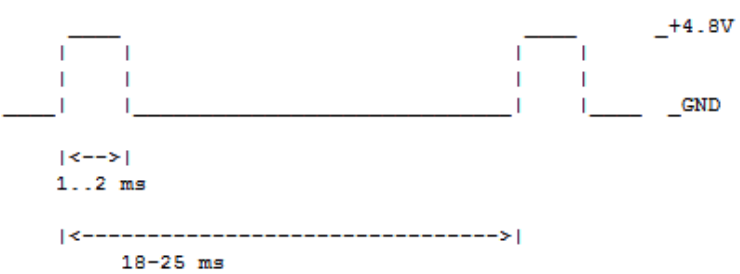

Şekil 6. RC servo motor için PWM sinyali (PWM waveform for the RC servo motor)

PWM sinyali ise 8 bitlik çözünürlüğe sahip ikili sayıcı kullanılarak oluşturulmuştur. PWM sinyali için gerekli matematiksel eşitlikler aşağıdaki gibi ifade edilir [9]:

$$
\begin{aligned}
& \text { Frame_Period }=T_{C L K} \times 2^{n} \\
& \text { Mark_Period }=T T_{C L K} \times \text { Mark_Value } \\
& \text { Duty_Cycle }=\frac{\text { Mark_Value }}{2^{n}}
\end{aligned}
$$

Yukarıda "Duty-cycle" olarak ifade edilen, PWM sinyalinin doluluk boşluk oranıdır. $\mathrm{Bu}$ orana göre servo motorlar konum alırlar. İfadelerde geçen "Mark_Value", PWM sinyalinin doluluk miktarını belirlemekte kullanılan onluk tabandaki sayıdır. Bu sayı mesafe bilgisinden hesaplanarak bulunur. Aracin cisme olan uzaklığına göre "Mark_Value" değeri değiştirilerek motorların konumu belirlenir. Modelsim programı kullanılarak VHDL aracılığı ile yazılan donanım kodundan elde edilen sentezleme sonucunun benzetimi yapılmıştır. Şekil 7'de görüldüğü gibi, verilere bağlı olarak robot kolu kontrolü için gerekli PWM'ler oluşturulan bu VHDL modül üzerinde üretilmiştir. 

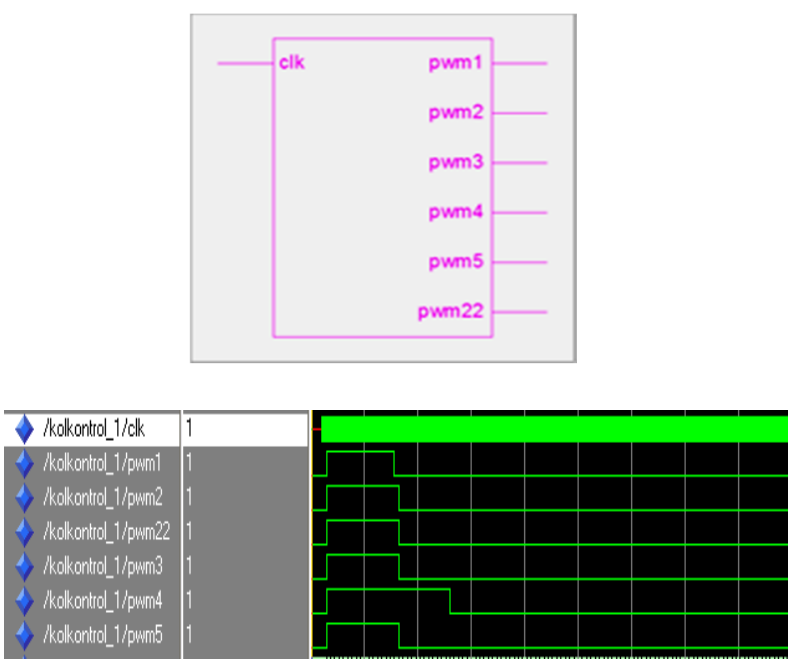

Sekil 7. Robot kolu VHDL kontrol bloğu ve ilgili Modelsim çıktıları (VHDL control block of the robot arm and the related Modelsim outputs)

\subsection{Mobil Araç Üzerindeki DC Motorların Kontrol Bloğu (Control block of the DC motors mounted under the mobile platform)}

Robot kolunun gezgin olmasını sağlamak için DC motorlara bağlı tekerleklerle hareket edebilen bir platform tasarlanmıştır. Motorun dönme hızı ve yönü, girişlere verilen sinyale göre ayarlanmıştır. Giriş sinyalleri, FPGA'da tasarlanan mobil araç motor kontrol bloğu ile kolaylıkla takip edilmiş ve mesafe bilgisine göre aracın konumu ayarlanmıştır. Mobil aracın hareket algoritmasını oluşturmak için gerekli durum bilgileri Tablo 1'de verilmiştir.

Tablo 1. Mobil araç yön kontrol tablosu (Direction control table of the mobile platform)

\begin{tabular}{|l|ll|ll|}
\hline $\begin{array}{c}\text { Mobil araç } \\
\text { hareketi }\end{array}$ & \multicolumn{2}{|c|}{ Sol tekerlekler } & Sağ tekerlekler \\
\hline Sola yönelme & $\begin{array}{l}\text { Dönüş hızını } \\
\text { arttır }\end{array}$ & $\begin{array}{l}\text { Dönüş hızını } \\
\text { azalt }\end{array}$ \\
\hline Sağa yönelme & $\begin{array}{l}\text { Dönüş hızını } \\
\text { azalt }\end{array}$ & $\begin{array}{l}\text { Dönüş hızını } \\
\text { arttır }\end{array}$ \\
\hline Düz ilerleme & Sabit hız & Sabit hız & \\
\hline
\end{tabular}

Mobil aracın ilerleme esnasında üç farklı durumu bulunmakta ve bu durumlara göre sağ ve sol tekerleklerin dönüş hızları ayarlanmaktadır. Tekerleklerin dönüş hızına göre mobil araç yön almakta ve bu işlem sürekli yapılmaktadır. Böylece mobil araç düz bir şekilde ilerleme yapabilmektedir. FPGA' lerin sağladığı kolaylıklardan biri de bol miktarda giriş çıkış portuna sahip olmasıdır. Şekil 8 'de görüldüğü gibi mobil aracın motorlarını kontrol etmek için toplam 12 tane sinyal oluşturulmuştur. $\mathrm{Bu}$ sinyallerden 8 tanesi motorlara giden giriş uçları, 4 tanesi ise enable yani yetkilendirme uçlarıdır. Robot kolu kontrolü için PWM sinyali oluşturulduğu gibi mobil aracın kontrolü için de PWM sinyalleri oluşturulmuştur. Ultrasonik sensörden gelen mesafe bilgisine göre motorlar, aracın konumunu belirlemek için konum alırlar.

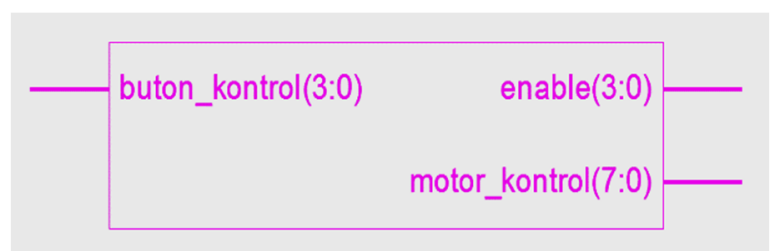

Şekil 8. Mobil araç motor kontrol bloğu (Motor control block of the mobile platform)

\subsection{Ultrasonik Sensör Kontrol Bloğu (Control block of} the ultrasonic sensor)

Mobil robot kolunun ilerleme esnasındaki dengesini yani düz gitmesini sağlamak için ultrasonik sensörden gelen bilgiler kullanılmıştır. Robot kolunun tutacağ1 cisimlerin boyutunu ölçmek için de aynı sensörden yararlanılmıştır. Bu çalışmada kullanılan ultrasonik sensör modülü ortama ses dalgası gönderir, gönderilen dalga cisme çarpıp geri döner. Dalganın gidip gelme süresi yardımıyla cisimlerin uzaklığı hesaplanır. Yapılan bu çalışmada $3 \mathrm{~cm}$ ile $300 \mathrm{~cm}$ arasını sağlıklı ölçebilen, hazır bir ultrasonik sensör modülü kullanılmıştır. Sensörle ölçüm yapılan mesafenin hesabı şu şekildedir (Eşitlik 4):

Mesafe $=\frac{\text { Toplam_süre } \times \text { ses_hlzl }}{2}$

Gönderilen ses sinyali engele çarpıp döneceği için ölçülen mesafe iki kat olur. Bunun için formülde ikiye bölme yer almaktadır. Toplam süre ise FPGA'nın çalışma frekansı ile ilgili olarak değişebilir. Spartan XC3S200 FPGA'nın çalışma saat frekansı 50 MHz'tir. Bu uygulamada DYP-ME007 ultrasonik sensörü kullanılmıştır. Sensörün çalışması için trigger yani tetikleme ucuna $10 \mu \mathrm{S}$ 'lik darbe uygulanmıştır. Uyarılan sensör tarafindan 8 tane ses dalgası gönderilir ve bekletilir. Echo ucu yani yansıma ucu, ses dalgası gönderilir gönderilmez lojik 1 olur ve dalga gelene kadar bekler, geri dönen dalga algilanınca echo ucu lojik 0 olur. Echo ucunun 1 olduğu zaman hesaplanarak mesafe ölçümü yapılır.

\section{CISIMLERIN TESPIT EDILMESİ (DETECTION OF THE OBJECTS)}

Ultrasonik sensör mobil aracın konumunu belirlemede, cisimleri tespit etmede ve cisimlerin boylarını ölçmede kullanılmıştır. Şekil 9'da görüldüğü gibi mobil robot kolu (A) ilerleme yönünde ilerlerken yol üstündeki farklı boyuttaki cisimleri (B, C, D) ayırt edebilmektedir. Yol üzerine yerleştirilen üç farklı boydaki cisimler dikdörtgenler prizması şeklinde olup, üzerlerine robot kolunun tutması için silindir şeklinde tutacak monte edilmiştir. Yol üzerinde yer alan dikdörtgenler prizması şeklindeki cisimleri boylarına göre; küçük cismi aracın üzerine, orta boylu cismi diğer tarafta arabadan uzak bir yere ve büyük olanı ise diğer tarafta arabaya yakın bir yere yerleştirebilmektedir. Cisimleri ayıklama durumları Tablo 2'de verilmiştir. 


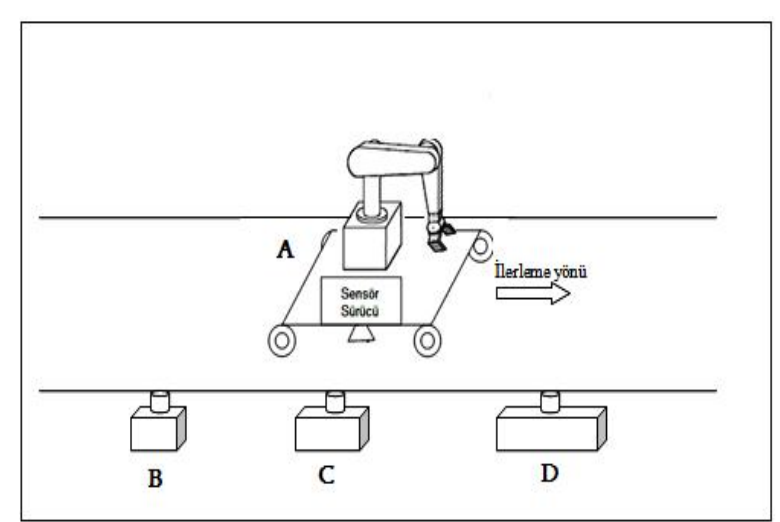

Şekil 9. Cisim tespit edilmesine yönelik blok diyagram (Conceptual diagram for the detection of objects)

Tablo 2. Cisim tespit ve yerleştirme tablosu (Table of object detection and placement)

\begin{tabular}{|c|c|c|c|}
\hline Cismin şekli & $\begin{array}{c}\text { Büyük } \\
\text { cisim }\end{array}$ & $\begin{array}{c}\text { Orta } \\
\text { boylu } \\
\text { cisim }\end{array}$ & $\begin{array}{c}\text { Küçük } \\
\text { cisim }\end{array}$ \\
\hline $\begin{array}{c}\text { Cismin } \\
\text { yerleştirileceği } \\
\text { Yer }\end{array}$ & $\begin{array}{c}\text { Aracın } \\
\text { diğer } \\
\text { yakın } \\
\text { tarafi }\end{array}$ & $\begin{array}{c}\text { Aracın } \\
\text { diğer } \\
\text { uzak } \\
\text { tarafi }\end{array}$ & $\begin{array}{c}\text { Araç } \\
\text { üzeri }\end{array}$ \\
\hline
\end{tabular}

Mobil robot kolu akış şemasının bir bileşeni olarak ultrasonik sensörle, cisimlerin boyu Şekil 10'da verilen blok diyagram yardımıyla ölçülerek gruplandırılmıştır.

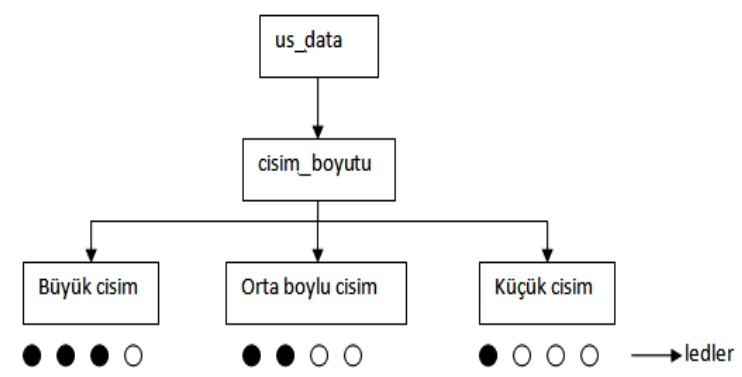

Şekil 10. Cisim boyutu algılama işlemi (Detection of the object sizes)

Spartan XC3S200 FPGA üzerinde yer alan 8 tane led kullanılarak cisimlerin boyları ölçülmüştür. $\mathrm{Bu}$ çalışmada sadece üç tane farklı boyutta cisim kullanıldığı için; cisimlerin boyları ledlerle ifade edilmiştir. Cisimlerin boylarını ölçüm tekniği olarak aşağıdaki genel hız-konum eşitliğinden yararlanılmıştır (Eşitlik 5):

cisim_boyutu $=a r a b a_{-}$hizi $\times$zaman

$\mathrm{Bu}$ eşitlikte arabanın hızına göre zaman ayarı yapılarak cisim boyu ölçülmüştür. Spartan XC3S200 FPGA'nın çalışma frekansı kullanılarak yeni bir sayıcı modülü tasarlanmış ve bu sayıcının frekansına göre zaman ayarı yapılmıştır.

\section{FPGA KAYNAK KULLANIMI VE KARŞILAŞTIRMA (FPGA UTILIZATION SUMMARY AND COMPARISON)}

Xilinx-ISE paket programı yardımıyla tasarım özeti görüntülenerek kaynak kullanım sonuçları elde edilmiştir. Tablo 3'te kaynak kullanım bilgileri ve oranları verilmiştir. $\mathrm{Bu}$ tablo sayesinde yapılan tasarımda kullanılan konfigüre edilebilir lojik blok (CLB) veya dilim (Slice) sayılarını, flip-flop sayısını, bak oku tablosu (LUT) sayılarını, giriş-çıkış port (IOB) sayısını ve bunların mevcut olan toplam kapasite miktarlarına oranları (\% olarak) görülmüştür. Tasarım gereksinim sonuçları sayesinde yapılacak olan güncellemeler için Spartan XC3S200 FPGA yongasının, mobil robot kolu sayısal tasarım blokları için fazlasıyla yeterli olduğu anlaşılmıştır. Tasarımın FPGA üzerine gerçeklenmesi sırasında toplam 26 adet pin ataması yapılmıştır. Pin atamalarının tasarımdaki port isimleri ve giriş-çıkış durumu Tablo 4'te verilmiştir.

Tablo 3. FPGA tasarım özeti (FPGA design summary)

\begin{tabular}{|l|l|l|l|}
\hline $\begin{array}{l}\text { Kullanılan } \\
\text { Lojik Yapı }\end{array}$ & $\begin{array}{l}\text { Kullanılan } \\
\text { sayı }\end{array}$ & $\begin{array}{l}\text { Mevcut } \\
\text { Kapasite }\end{array}$ & $\begin{array}{l}\text { Kullanım } \\
\text { oranı }\end{array}$ \\
\hline $\begin{array}{l}\text { Filip-flop } \\
\text { dilim sayısı }\end{array}$ & 348 & 3840 & $\% 9$ \\
\hline $\begin{array}{l}\text { 4 girişli Bak } \\
\text { Oku Tablosu } \\
\text { (LUT) }\end{array}$ & 761 & 3840 & $\% 19$ \\
\hline $\begin{array}{l}\text { Kullanılan } \\
\text { dilim (Slice) }\end{array}$ & 507 & 1920 & $\% 26$ \\
\hline $\begin{array}{l}\text { Toplam 4 } \\
\text { girişli LUT }\end{array}$ & 977 & 3840 & $\% 25$ \\
\hline $\begin{array}{l}\text { Giriş/çıkış pin } \\
\text { (IOB) }\end{array}$ & 26 & 173 & $\% 15$ \\
\hline $\begin{array}{l}\text { Saat darbesi } \\
\text { (GCLKs) }\end{array}$ & 3 & 8 & $\% 37$ \\
\hline
\end{tabular}

Literatürde fonksiyonel olarak bu çalışmadaki robot kolu sistemi ile birebir örtüşen bir mobil robot kolu mekanizmasına henüz rastlanamadığından (hem FPGA tabanl, hem mobil ve hem de 5 eksenli olması bakımından özgün bir çalışmadır), burada performansa dayalı bir karşılaştırma yapılamamıştır. Ancak bu çalışma, tasarım teknolojisi (DSP, FPGA, veya Mikroişlemci gibi), mobil olup olmama durumu, kol serbestlik derecesi, cisim veya konum algılama metodolojisi gibi kriterler açısından, literatürdeki bazı örnek FPGA tabanlı çalışmalarla Tablo 5 üzerinde kategorik olarak karşılaştırılmıştır. Literatürde, bu çalışmada olduğu gibi ultrasonik ses dalgası yansimasinı (echo) konum belirleme ve cisim algilamada kullanarak yapılan robot uygulamalarına rastlanmaktadır. Bunlara örnek olarak [10], [11], [12] nolu çalışmalar verilebilir. Ancak bunlarda kullanılan tasarım teknolojisi sadece FPGA tabanlı olmadığından ve de robot tipi, esneklik dereceleri bu çalışmadakinden farklı olduğundan karşılaştırmaya dahil edilmemiştir. 
Tablo 4. I/O Port isimleri ve durumları tablosu (I/O port names and the related port states)

\begin{tabular}{|l|l|}
\hline I/O Port ismi & $\begin{array}{l}\text { Port } \\
\text { Durumu }\end{array}$ \\
\hline Aç-kapa & giriş \\
\hline Clk & giriş \\
\hline Echo & giriş \\
\hline 8 adet led & ç1kş̧ \\
\hline 6 adet PWM & ç1kş̧ \\
\hline 8 adet motor kontrol & ç1k1ş \\
\hline Trigger & çk1ş \\
\hline
\end{tabular}

Tablo 5. Kategorik Karşılaştırma tablosu (Categorical Comparison table)

\begin{tabular}{|c|c|c|c|c|}
\hline 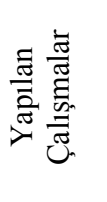 & 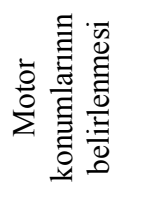 & 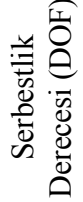 & 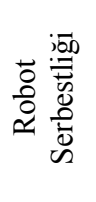 & 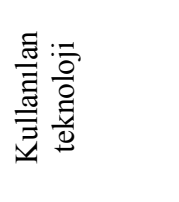 \\
\hline $\begin{array}{l}\mathrm{Bu} \\
\text { çalışma }\end{array}$ & $\begin{array}{l}\text { Ultrasonik } \\
\text { sensör }\end{array}$ & 5 & Mobil & FPGA \\
\hline [2] & $\begin{array}{l}\text { Zig-Bee ile } \\
\text { Kablosuz } \\
\text { olarak } \\
\text { kontrol }\end{array}$ & 4 & Mobil & FPGA+ARM \\
\hline [3] & $\begin{array}{l}\text { Dönen } \\
\text { kodlayıcı, } \\
\text { ters } \\
\text { kinematik } \\
\text { hesaplama }\end{array}$ & 5 & Sabit & FPGA \\
\hline [4] & $\begin{array}{l}5 \text { farklı } \\
\text { sensör }\end{array}$ & Yok & Mobil & FPGA+ARM \\
\hline [5] & $\begin{array}{l}\text { Dönen } \\
\text { kodlayıcı, } \\
\text { ters } \\
\text { kinematik } \\
\text { hesaplama }\end{array}$ & 5 & Sabit & FPGA \\
\hline
\end{tabular}

\section{SONUÇLAR (CONCLUSIONS)}

$\mathrm{Bu}$ çalışma sonunda, 5 eksenli mobil bir robot kolunun, üzerine monte edildiği mobil araçla birlikte kontrolü, VHDL donanım programlama dili yardımı ile yapılan tasarım yoluyla tek bir FPGA yongası üzerinde (Spartan XC3S200) donanımsal olarak gerçeklenmiştir. Sistem için gerekli diğer analog modüller (motor sürücü ve güç devreleri) ayrıca tasarlanmış ve aynı mobil platform üzerine monte edilmiştir. Benzetimlerde Modelsim programı kullanılmıştır. Tasarlanan sistemde bileşen sayısının artmasına rağmen FPGA' in sağladığı esneklikle sistemler arası zamanlama açısından uyum kolaylıkla sağlanmıştır. Tasarım FPGA deneme kiti üzerinde reel olarak gerçeklenmiş ve deneysel testler yapılmıştır. Mobil robot kolunun tüm beklenen işlevlerini başarıyla yerine getirdiği görülmüştür.

Sonuç olarak, donanım programlama dilleri yardımıyla yapılacak olan robot kolu tasarım ve uygulamalarına örnek teşkil edecek çok eksenli, tümüyle otonom olarak çalışabilen, esnek bir mobil robot kolu prototipi gerçeklenmiştir. Tasarım sırasında karmaşık ters kinematik denklemler kullanılmamıştır. Literatürde ters kinematik hesaplama kullanılmayan robot uygulamalarına rastlanmaktadır. Çift kollu robot uygulamaları ile hem işlemci hem FPGA kullanımını içeren hibrit tasarımlara literatürde rastlanmaktadır. Ancak bu çalışmalar çok daha karmaşık yapılar oldukları için buradaki karşılaştırmaya mümkün olduğunca dahil edilmemişlerdir.

\section{Bilgilendirme:}

$\mathrm{Bu}$ çalışma, Kocaeli Üniversitesi Bilimsel Araştırmalar Şube Müdürlüğü BAP- Mikroelektronik Laboratuvarı kapsamında desteklenmiştir.

\section{KAYNAKLAR (REFERENCES)}

1. Meshram, U., Bande, P., Dwaramwar, P. A., Harkare, R. R., "Robot Arm Controller Using FPGA", IMPACT'2009, 8-11, 2009.

2. Xu, M., Zhu, W. ve Zou, Y.," Design of a Reconfigurable Robot Controller Based on FPGA", Fifth IEEE International Symposium on Embedded Computing, 216-222, 2008.

3. Cho, J. U., Le, Q. N., Jeon, J. W., "An FPGABased Multiple- Axis motion control chip" IEEE Transactions on Industrial Electronics, Cilt 56, No 3, 856-870, 2009.

4. Samuelsen, D., Graven, O. H., "Low cost robots used for practical assignments in programming modules”'IEEE-ICELIE'09, 80-85, 2009.

5. Kung, Y-S., Shu, G-S., " Development of a FPGA-based Motion Control IC for Robot Arm", ICIT IEEE International Conference, 13971402, 2005.

6. Karci, H., Tangel, A. "FPGA Tabanlı 5-Eksenli Mobil Robot Kolu Tasarımı ve Uygulaması", ELECO'2013, Bursa, Türkiye, 2013.

7. Monmasson, E. ve Cirstea, M., "FPGA Design Methodology for Industrial Control Systems - A review," IEEE Transactions on Industrial Electronics, Cilt 54, No 4, 1824-1842, 2007.

8. Meshram, U. ve Harkare, R.R., "FPGA Based Five Axis Robot Arm Controller" International Journal of Electronics Engineering, Cilt 2, No 1, 209-211, 2010.

9. Lawman,G., "Pulse-Width Modulation in Xilinx Programmable Logic", Application Brief, 1-3, 1995.

10. Kuc, R., Kirichenko, M. F., Lepekha, M. P., "Adaptive and Mobile Biomimetic Sonar Recognizes Objects From Echos" OCEANS'99 MTS/IEEE.Riding the Crest into 21st Century Cilt 2, 707-712, 1999.

11. Trabelsi, M., Ait-Oufroukh, N., Lelandais, S., "Localization Method for a Rehabilitation Mobile Robot using Visual and Ultrasonic Information", 
Proceedings of the 2007 IEEE 10th International Conference on Rehabilitation Robotics, 164-170, 2007.

12. Liu, H., Stoll, N., Junginger, S., Thurov, K., "A New Method for Mobile Robot Arm Blind
Grasping Using Ultrasonic Sensors and Artificial Neural Networks", Proceeding of the IEEE International Conference on Robotics and Biomimetics (ROBIO), 1360-1364, 2013. 